\title{
PELATIHAN PEMANFAATAN SARANA TEKNOLOGI INFORMASI DAN KOMUNIKASI DENGAN PENYIMPANAN BERBASIS CLOUDCLOUD DI SDN SEMANGAT DALAM 1
}

\author{
Agus Alim Muin'), Erfan Karyadiputra1), Indu Indah Purnomo²) \\ 1) Program Studi Sistem Informasi, Fakultas Teknologi Informasi, Universitas Islam Kalimantan Muhammad Arsyad \\ Albanjari Banjarmasin, Banjarmasin, Kalimantan Selatan, Indonesia \\ 2)Program Studi Teknik Informastika, Fakultas Teknologi Informasi, Universitas Islam Kalimantan Muhammad Arsyad \\ Albanjari Banjarmasin, Banjarmasin, Kalimantan Selatan, Indonesia \\ Corresponding author: Agus Alim Muin \\ E-mail : Alim.blues@gmail.com
}

Diterima 11 November 2021, Disetujui 28 November 2021

\begin{abstract}
ABSTRAK
Pengabdian kepada masyarakat ini bertujuan membantu guru dan para staff yang masih mengalami kesulitan dalam hal memanfaatkan media penyimpanan berbasis cloud di SDN Semangat Dalam $1 \mathrm{Kab}$. Batola Kalimantan Selatan,untuk permasalahan pengabdian kepada masyarakat ini memfokuskan bagaimana para guru dan staff di sekolahan SDN Semangat Dalam 1 dapat mahir dalam menggunakan media penyimpanan seperti google drive,dropbox,one drive dan icloud untuk membantu proses pembelajaran serta menjadi media penyimpanan yang efektif dan efisien saat ini. Dengan dilakukannya pengabdian masyarakat ini membantu para guru dan staff di sekolahan SDN Semangat Dalam 1 memanfaatkan media penyimpanan berbasis cloud sehingga menjadi alternatif untuk penunjang proses pembelajaran dan proses pekerjaan.
\end{abstract}

Kata kunci: cloud; guru; media penyimpanan; pelatihan.

\begin{abstract}
This community service aims to help teachers and staff who are still experiencing difficulties in terms of utilizing cloud-based storage media in SDN Semangat Dalam 1 Kab. Batola South Kalimantan, for community service problems this focuses on how teachers and staff in SDN Semangat Dalam 1 schools can be proficient in using storage media such as google drive, dropbox, one drive and icloud to help the learning process as well as become an effective and efficient storage medium today. With this community service helps teachers and staff in SDN Semangat Dalam 1 schools utilize cloud-based storage media so that it becomes an alternative to support the learning process and work process.
\end{abstract}

Keywords: cloud; teacher; storage media; training.

\section{PENDAHULUAN}

Seiring perkembangan ilmu pengetahuan dan teknologi, menuntut terciptanya sumber daya manusia yang handal dan memiliki kemampuan sejalan dengan perkembangan era teknologi informasi. Ketersediaan sumber daya manusia yang profesional terutama guru adalah modal paling utama untuk meningkatkan kualitas sumber daya manusia khususnya dalam bidang pendidikan,oleh sebab itu diperlukan upaya peningkatan kemampuan para pengajar dan staff dalam mengikuti perkembangan teknologi informasi dalam rangka membantu proses belajar mengajar, hal ini sesuai dengan undang-undang republic Indonesia no 14 tahun 2005 tentang guru dan dosen yang menjelaskan beberapa kompetensi yang harus dimiliki seorang guru professional, salah satunya kemampuan guru dalam memanfaatkan teknologi informasi dan komunikasi (TIK) dalam proses belajar mengajar.(Pemerintah RI, 2005).

Pendidikan nasional adalah pendidikan yang berdasarkan Pancasila dan UndangUndang Dasar Negara Republik Indonesia Tahun 1945 yang berakar pada nilai-nilai agama, kebudayaan nasional Indonesia dan tanggap terhadap tuntutan perubahan zaman. (Al-Faraji, 2006)

Perkembangan teknologi informasi yang semakin pesat di era globalisasi saat ini tidak bisa dihindari lagi pengaruhnya terhadap dunia pendidikan.Tuntutan global menuntut dunia pendidikan untuk selalu dan senantiasa menyesuaikan perkembangan teknologi terhadap usaha dalam peningkatan mutu pendidikan, terutama penyesuaian penggunaan nya bagi dunia pendidikan khususnya dalam proses pembelajaran.(Haris Budiman., 2017) 
Dari observasi yang dilakukan di SDN Semangat Dalam 1 didapatkan, guru dan staff masih belum bisa memanfaatkan media penyimpanan data yang berbasis cloud seperti penggunaan google drive,dropbox,one drive dan cloud sebagai media penyimpanan yang penunjang pelaksanaan pengajaran dan pekerjaan. Dengan adanya pengabdian kepada masyarakat ini diharapkan dapat meningkatkan keterampilan guru dalam memanfaatkan sarana teknologi informasi dan komunikasi sebagai alat untuk membantu pembelajaran dan pekerjaan. (Anjir et al., 2019)

\section{METODE}

Pengabdian kepada masyarakat ini dilaksanakan di SDN Semangat Dalam 1, di jalan semangat dalam, kec.Alalak,kabupaten barito kuala, Kalimantan selatan 70582,untuk peserta pengabdian karena menyesuaikan waktu dan tempat kegiatan,pengabdian kepada masyarakat ini di hadiri 10 peserta dengan 8 guru dan 2 staff yang di tunjuk langsung oleh kepala sekolah untuk mewakili mengikuti pengabdian kepada masyarakat.

1. Tahap pengumpulan data

a. Tahap survei

Metode ini bertujuan untuk mendapatkan informasi tentang kebutuhan apa yang diperlukan untuk meningkatkan kemampuan para guru dan staff terkait teknologi informasi untuk membantu pembelajaran dan pekerjaan

b. Tahap wawancara dan kerjasama

Bertujuan untuk menentukan menentukan waktu pengabdian masyarkat serta jumlah guru dan staff yang akan mengikuti pelatihan dan juga adanya surat persetujuan dari sekolahan tentang kegiatan pengabdian kepada masyarakat yang akan dilakukan

c. Tahap pretest

Metode ini bertujuan untuk melihat dan mengukur sejauh mana pengetahuan dari para guru dan staff tentang materi pelatihan terkait dengan media penyimpanan berbasis cloud serta untuk mempersiapakan kedalaman materi yang perlu disampaikan,metode ini di berikan sebelum dilakukanya penyampaian materi

d. Tahap posttest

Metode ini bertujuan untuk melihat dan mengukur sejauh mana peningkatan pengetahuan dari para guru setelah mendapatkan materi terkait dengan pelatihan media penyimpanan berbasis cloud serta untuk menentukan materi apa yang masih perlu di tekankan,metode ini dilakukan setelah pemberian materi selesai

2. Tahap pelaksanaan kegiatan

a. Tahap presentasi

Metode presentasi berupa sosialisasi kegiatan untuk meningkatkan pengetahuan kepada guru dan staff di SDN semangat dalam 1 yang berkaitan dengan materi memanfaatkan penyimpanan berbasis cloud.

b. Tahap pelatihan

Metode pelatihan dan pendampingan ini bertujuan untuk para guru agar dapat mencoba lansung bagaimana cara memanfaatkan media penyimpanan berbasis cloud seperti google drive,dropbox,one drive dan icloud yang tentunya dengan di dampingi oleh tim pengabdian kepada masyarakat agar semua berjalan sesuai yang di inginkan.

c. Tahappraktek mandiri

Metode ini bertujuan untuk memberikan waktu kepada para guru dan staff untuk praktek secara mandiri agar lebih mengasah kemampuan dalam hal memanfaatkan media penyimpanan data berbasis cloud serta dalam mengukur tingkat kemahiran dari guru dan staff setelah mendapatkan pelatihan dan pendampingan.

\section{HASIL DAN PEMBAHASAN}

Berdasarkan dari metode pelakasanaan yang dilakukan mendapatkan hasil sebagai berikut :

a. Tahap persentasi

Metode persentasi yang dilakukan berjalan dengan baik ini dibuktikan dengan antusiasnya para guru dan staff dalam memperhatikan materi yang diberikan serta secara aktif memberikan pertanyaan terkait materi apabila mereka merasa belum terlalu jelas.

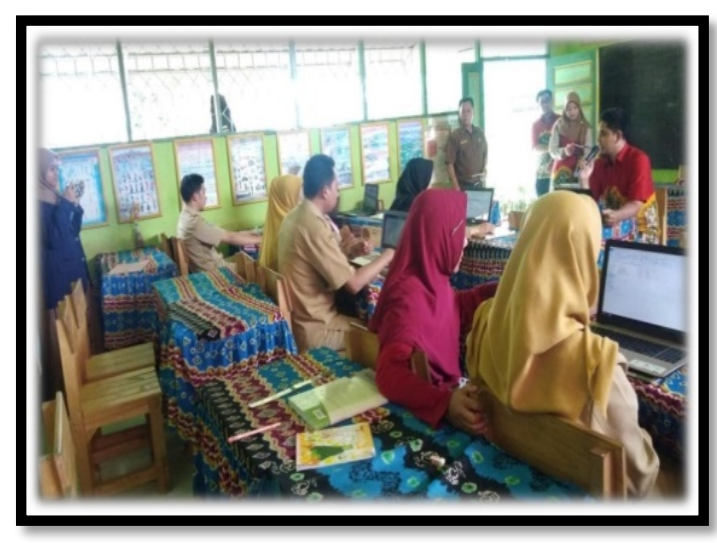

Gambar 1. Penyampaian Materi

b. Tahap pelatihan

Metode pelatihan yang dilakukan berjala dengan baik ini dibuktikan dengan dapat melaksanakannya dari materi yang diberikan serta secara aktif bertanya pemateri atau tim pendamping pengabdian apabila ada yang kurang dimengerti tentang penerapan dari materi yang sudah di sampaikan. 


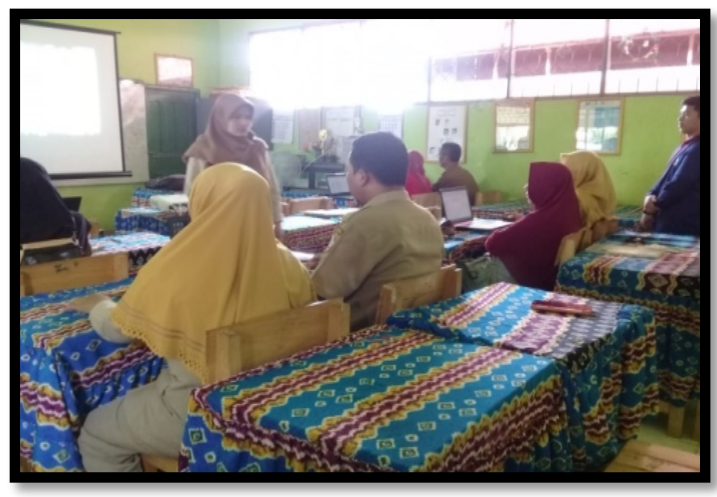

Gambar 2. Pendampingan

\section{c. Tahap Praktek mandiri}

Praktek mandiri yang dilakukan berjalan dengan baik ini di buktikan dengan dapat berhasilnya peserta membuat dan mempraktekanya dari materi yang di sampaikan dari mempraktekan google drive,dropbox,one drive dan icloud sehingga dapat menjadi penunjang kelancaran dalam proses belajar mengajar.

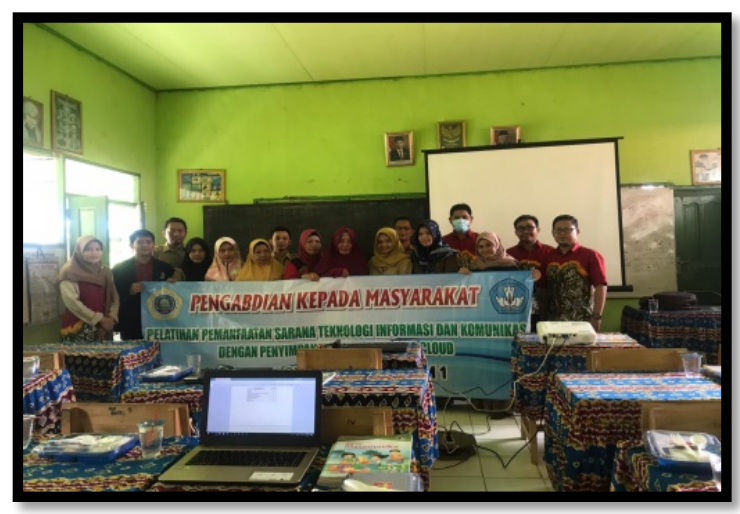

Gambar 3.Sesi setelah selesai pengabdian

\section{d. Kuisioner post test}

Kuisioner post test berhasil dengan baik dengan diberikannya kuisioner tentang pengetahuan materi,dari kuisioner yang di berikan semua dapat mempratekan dan memahami materi yang di sampaikan dengan persentasi mencapai $100 \%$.

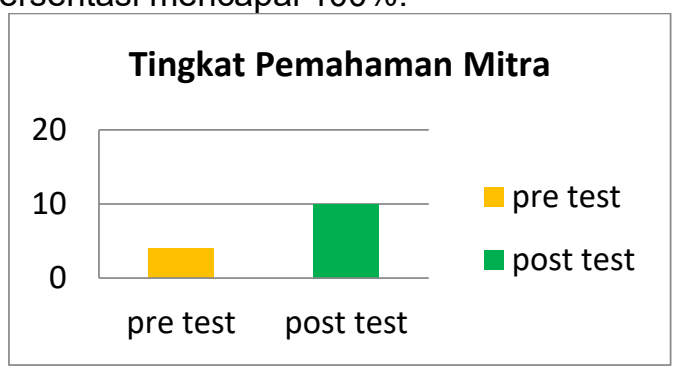

Gambar 4. Grafik tingkat pemaham

\section{SIMPULAN DAN SARAN}

Kegiatan pengabdian kepada masyarakat yang dilaksanakan di SDN
Semangat Dalam I, Kecamatan Alalak Kabupaten Barito Kuala secara umum berjalan dengan lancer seperti dalam hal penyampaian materi,target peserta,pelatihan dan antusiasme peserta serta hasil pemahaman peseta selama mengikuti pengabdian kepada masyarkat.

Dari pengabdian masyarakat yang sudah dilakukan disarankan sebaiknya ada pengabdian selanjutnya serta selalu melihat secara berkala bagaimana perkembangan mitra terkait pelatihan yang sudah dilakukan serta kepada mitra sebaiknya terus mengasah kemampuan masing-masing terkait pelatihan yang sudah diberikan agar menjadi peningkatan kemampuan yang tepat guna

\section{UCAPAN TERIMAKASIH}

Terimakasih kepada kepala dekan fakultas teknologi infromasi, telah menyetujui pelaksanaan pengabdian kepada masyarakat. Terimakasih untuk kepala sekolahan SDN Semangat Dalam 1 atas persetujuan kegiatan pengabdian kepada masyarakat. Ucapan terimakasih yang terakhir adalah kepada tim pelaksana dan teman-teman mahasiswa program studi system informasi universitas islam Muhammad arsyad al banjari banjarmasin yang telah membantu serta berbagi ilmu dan pengetahuan kepada masyarakat.

\section{DAFTAR RUJUKAN}

Al-Faraji, H. A. (2006). No Title. Vascular Embolotherapy, 107-118.

Anjir, D., Kota, P., Kec, I. I., Pasar, A., \& Batola, K. A. B. (2019). IJCCS, Vol.x, No.x,. 5(x), 78-86.

Haris Budiman. (2017). Peran Teknologi Informasi Dan Komunikasi Dalam Pendidikan. Al-Tadzkiyyah: Jurnal Pendidikan Islam, 8(1), 31-43.

Pemerintah RI. (2005). Undang-undang Republik Indonesia Nomor 14 Tahun 2005 tentang Guru dan Dosen. Produk Hukum.

Ismawan, F., Irfansyah, P., \& Apriyani, D. D. (2018). Pengoptimalan Cloud StorageGoogle Drive sebagai Media Pembelajaran untuk Guru SMP dan SMA. Jurnal PkM (Pengabdian kepada Masyarakat), 1(01), 61-70. 